\title{
ENSAIO
}

OS (DES)ENCONTROS DA PESQUISA NO AEMPO-ESPAÇO AMAZÔNICO: UM ENSAIO SOBRE PRODUÇÃO DE CONHF CIMENTO COMO ABERTURA À APRENDIZAGEMI

Research encounters in the amaron time-sppermanent learning.

I (dis)incontri della ricerca nello or ario-tempo amazzonico: un saggio sulla produzione di conoscenza come apertura all'apprendiminto.

\section{Alcindo Antônio Ferla}

Médico, doutor em educação, professor do Programa de Pós-Graduação em Saúde Coletiva da Universidade Federal do Rio Grande do Sul (UFRGS), pesquisador visitante sênior do Laboratório de História, Políticas Públicas e Saúde na Amazônia (LAHPSA) - Fiocruz Amazônia/FAPEAM.

E-mail: alcindo.ferla@ufrgs.br

\section{Renata Flores Trepte}

Psicóloga. Mestranda em Saúde Coletiva pela Universidade Federal do Rio Grande do Sul.

E-mail: renata.trepte@gmail.com

\section{Júlio Cesar Schweickardt}

Cientista social, doutor em História das Ciências e da Saúde e pesquisador do Laboratório de História, Políticas Públicas e Saúde na Amazônia (LAHPSA) - Fiocruz Amazônia e professor do Programa de Pós-Graduação Stricto Sensu em
Condições de Vida e Situações de Saúde na Amazônia (PPGVida).

E-mail: julio.ilmd@gmail.com

\section{Rodrigo Tobias de Sousa Lima}

Cirurgião Dentista, Doutor em Saúde Pública, pesquisador do Laboratório de História, Políticas Públicas e Saúde na Amazônia (LAHPSA) - Fiocruz Amazônia e professor do Programa de PósGraduação Stricto Sensu em Condições de Vida e Situações de Saúde na Amazônia (PPGVida). E-mail: tobiasrodrigo@gmail.com

\section{Ardigò Martino}

Médico, Doutor em Cooperação Internacional e Desenvolvimento Sustentável, Especialista em Saúde Pública, pesquisador do Centro de Estudos e Pesquisa em Saúde Internacional e Intercultural Universidade de Bologna. E-mail: ardigo.martino@unibo.it

\section{Resumo}

Narrativa da experiência do trabalho de campo de pesquisa avaliativa sobre o Programa Mais Médicos realizada no Município de São Gabriel da Cachoeira, no Estado do Amazonas. Por meio da narrativa, busca-se refletir sobre a

necessidade de abertura à aprendizagem a partir da diversidade do local na metodologia das pesquisas que analisam contextos diversos, em particular no âmbito das análises de políticas públicas. A diversidade de situações

\footnotetext{
' Este trabalho é fruto de pesquisa financiada pela Fundação de Amparo à Pesquisa do Estado do Amazonas (FAPEAM) e integrante da Rede-Observatório do Programa Mais Médicos.
} 


\section{OS (DES)ENCONTROS DA PESQUISA NO TEMPO-ESPAÇO AMAZÔNICO}

encontradas no campo empírico é utilizada para refletir sobre aspectos operacionais, questões metodológicas e relações entre teoria e prática nas pesquisas sociais. Utilizando a metáfora do embrenhar, com sentido de estar em situação diversa do habitual, foram sendo analisadas questões singulares da pesquisa que destacam a contribuição do campo empírico de implementação de políticas no território amazônico para o fazer da pesquisa. Entre as questões que o empírico levantou para a pesquisa, quando colocado em diálogo transversal com a teoria e com a metodologia da pesquisa, está o desenvolvimento da atenção básica a partir do encontro entre perspectivas diversas dos profissionais do Programa e os profissionais vinculados anteriormente às equipes. Sugere-se que a pesquisa, para articular o geral e o específico, a teoria e as práticas, seja compreendida como educação permanente dos pesquisadores. Palavras-chave: Programa Mais Médicos; Pesquisas avaliativas; Atenção básica em saúde; Metodologia de pesquisa social.

\section{Abstract}

The article refers to the experience of evaluative research on the 'More Doctors' Program in São Gabriel da Cachoeira, Amazonas, Brazil. The methodology was based on the narrative, as well as learning by the diversity of research methodologies used to analyze public policies in the specific context. Thus, the research field was used to reflect on operational aspects, methodological issues and relations between theory and practice in social research. The metaphor of "embarrassing", which means "being in a different context than usual" was used to analyze specific research themes, highlighting ways of conducting research on public policies in the Amazonian territory. The research in the territory produced a transversal dialogue between the results and the theoretical and methodological references, as well as the development of the primary health care from the meeting of the professionals of the More Doctors Program and the others previously linked to the teams. Therefore, it is suggested that the research process that articulated general and specific, as well as theory and practice, can be understood the educational actions for researchers. Key words: More Doctors Program; evaluative research; primary health care; methodology of social research.

\section{Sommario}

L'articolo si riferisce all'esperienza di ricerca valutativa realizzata nel municipio di São Gabriel da Cachoeira, nello stato di Amazonas, Brasile, nell'ambito del Programma Mais Médicos. L'articolo si focalizza sull'apprendimento mediato della diversità e dalla diversificazione delle metodologie di ricerca basate sul contesto, e si sofferma sulle possibili ripercussioni sul "campo" delle analisi delle politiche pubbliche svolte attraverso questa prospettiva. Nella ricerca, la peculiarità delle condizioni presenti nel "campo", viene utilizzata per riflettere sia su aspetti operativi, sia sulle questioni metodologiche e sia sugli effetti sul campo delle relazioni tra teoria e pratica. Utilizzando la metafora del "embrenhar" ovvero "essere in un contesto differente da quello abituale" sono stati collocati in analisi temi specifici della ricerca nel tentativo di mettere in risalto quali contributi alla ricerca stessa sono apportati dallo studio dell'implementazione delle politiche nel contesto reale del territorio. Tra le questioni sollevate dall'incrocio tra le informazioni raccolte ed i quadri teorico-metodologici della ricerca sottolineamo il potenziale, in termini di sviluppo delle cure primarie, rappresentato dall'incontro tra le diverse prospettive dei professionisti legati al Programma Mais Medicos e quelli precedentemente legati alle equipes. Infine si suggerisce che la ricerca, per 


\section{OS (DES)ENCONTROS DA PESQUISA NO TEMPO-ESPAÇO AMAZÔNICO}

ricostruire le articolazioni tra generale e specifico, tra teoria e pratiche, debba essere intesa come una attività di educazione permanente dei ricercatori. Keywords: Programma "Più Medici"; ricerca valutativa; Cure Primarie; metodologia della ricerca sociale.

Introdução

Embrenhar, v. t. Meter, esconder (nas brenhas, no mato); p. meter-se, internar-se (nos matos, nas brenhas). ${ }^{1}$

Nos embrenhamos, na Amazônia, na pesquisa. $\mathrm{O}$ dicionário Aurélio ${ }^{1}$ atenta que $\mathrm{O}$ verbete brenha significa tanto floresta, quando "situação confusa". O cotidiano de pesquisa não é mais que uma metodologia do embrenhar-se: haver-se com o não previsto, seja na floresta ou nas paredes da universidade o pesquisar nos desafia a dobrar o pensamento, a lançar-nos ao novo. Senão, apenas mais do mesmo!

Este relato apresenta as vivências de uma equipe de pesquisa no tempo-espaço da Amazônia. Em um projeto cujo objeto é analisar - Programa Mais Médicos (PMM) na perspectiva do desenvolvimento da atenção básica, a ida a campo lança foco sob o trabalho em saúde dos médicos inseridos no PMM e das equipes das quais participam, utilizando como referência as categorias de trabalho vivo em ato e as tecnologias do cuidado (duras, leves-duras, leves), para compreender os efeitos e as relações de trabalho em saúde na sua dimensão micropolítica. Uma das etapas da pesquisa consiste em realizar entrevistas com profissionais integrantes do PMM, este relato refere-se a uma das incursões a campo: o município de São Gabriel da Cachoeira. O tema da gestão do trabalho em saúde está presente nas políticas públicas que percorrem os caminhos da formação, educação, produção, modelos de contratação, provimento, fixação e organização do cuidado. Considerando que o processo de avaliação em si é baseado um especifico posicionamento ético-político, pois se propõe produzir algum efeito no campo das práticas, os valores que informam o sistema de avaliação tendem a produzir um efeito pedagógico, interferindo com os valores e as práticas dos sujeitos envolvidos: gestores, profissionais, usuários e comunidade. ${ }^{2}$ Desse modo, o projeto de antemão já se propõe a contribuir com a formulação e aprimoramento de políticas públicas para a questão da gestão do trabalho em regiões de grande diversidade social. A atenção básica em saúde se faz num determinado território, que, no caso das populações amazônicas, está constantemente se ajustando ao regime das águas, com a mistura de culturas e modos de andar no território. As políticas de saúde necessitam de um olhar mais atento para essas realidades específicas, impactando sobre a qualidade dos 


\section{OS (DES)ENCONTROS DA PESQUISA NO TEMPO-ESPAÇO AMAZÔNICO}

serviços e nos processos de trabalho das equipes de saúde.

O território rural e ribeirinho se configura num conceito múltiplo e amplo, que ultrapassa os limites geográficos e abrange os modos de vida e suas territorialidades, inclusive para produzir sua saúde. Entende-se rural como envolvimento das diferentes realidades da população amazônica, que vive em comunidades e em consonância com a floresta, independente da sua localização, dentro ou longe da cidade. $E$ a pesquisa tem que entender-se e ajustar-se a esses outros modos de levar a vida, meter-se em campo, embrenhar-se.

O plano e os possíveis: uma pesquisa atravessada por circunstâncias

\section{- Plano de trabalho:}

\section{Primeiro dia:}

a) Manhã: reunião com a equipe e revisão do plano de trabalho de campo, revisão do material e dos roteiros de entrevista. Confirmação dos agendamentos. b) Tarde: deslocamento aéreo Manaus/Tefé e Tefé/São Gabriel da Cachoeira. Chegada no destino. c) Noite: Deslocamento ao hotel. Jantar. Descanso.
Segundo dia:

a) Manhã: contato e entrevista com gestor municipal. b) Tarde: deslocamento até a USF 1. Entrevistas. Deslocamento até a USF 2. Entrevistas. c) Noite: Avaliação do desempenho no trabalho de campo. Ajustes na técnica das entrevistas. Avaliação e planejamento das atividades subsequentes. Jantar. Descanso.

\section{Terceiro dia:}

a) Manhã: deslocamento até aldeia indígena. b) Tarde: Encontro com equipe de saúde indígena. Entrevistas. Deslocamento. c) Noite: Avaliação do desempenho no trabalho de campo. Avaliação e planejamento das atividades subsequentes. Jantar. Descanso.

\section{Quarto dia:}

a) Manhã: Divisão da equipe. Deslocamento até as Unidades 3 e 4. b) Tarde: Deslocamento ao hotel. c) Noite: Avaliação do desempenho no trabalho de campo. Jantar. Descanso.

\section{Quinto dia:}

Retorno a Manaus. Deslocamento.

- Executando o plano:

O início do plano de trabalho do primeiro dia foi conforme o previsto. Por volta de 11 horas da manhã, após revisão do script 


\section{OS (DES)ENCONTROS DA PESQUISA NO TEMPO-ESPAÇO AMAZÔNICO}

desenhado para o trabalho de campo, nos deslocamos ao aeroporto para a viagem até São Gabriel da Cachoeira, com conexão em Tefé. A equipe estava agitada. Um humor ingênuo procura disfarçar um quê de ansiedade. Procedimentos junto à companhia aérea foram realizados e ingressamos na sala de embarque. Chamada para o embarque no horário. $\mathrm{O}$ avião é um modelo turboélice. Sorrisos nervosos constatando que o plano do trabalho de campo estava fluindo: assopra a responsabilidade para manter tudo no roteiro programado. Primeira baixa: um celular ficou esquecido, mas no cômputo geral, não fará falta. Ficou apenas o celular que sempre é esquecido!!! A viagem segue. O Comandante informa que as condições meteorológicas estão favoráveis e que há apenas algumas formações com precipitação próximas ao aeroporto de destino.

Melhor descansar um pouco, é a mensagem que atravessa o corpo dos pesquisadores. Em seguida o serviço de bordo, e novo pretexto para risos nervosos, agora com detalhes do uniforme da aeromoça. Recuperados do entretenimento de bordo, eis que a floresta está branca: nuvens cobrem a visão de tudo, exceto uns retalhos de azul e verde aqui e acolá. Para parte da equipe, paisagem usual; para os visitantes, imagens impensáveis. Procedimentos para o pouso, informa o comandante, com o alerta de que há chuva forte na cabeceira da pista. Aproximação e arremetida: sem condições de visibilidade mínima da pista. Tensão!! Procedimentos de espera e, nos círculos que a aeronave faz enquanto aguardamos as condições melhorarem, aqui e ali pedaços de floresta, rios, igarapés e muito verde. E nenhuma evidência de ocupação humana! Bom, parece que chegamos num lugar que está fora do pensamento de quase todos. Uma nuvem densa de chuvas adiante, fechando como cortina do alto até o solo, mostra que estamos na época das chuvas. E chuva, aqui, é precipitação torrencial!

Nova tentativa de pousar, quando o nível de combustível chega no limite da viabilidade de espera, e, dessa vez, com êxito. Um pouso suave, que levanta aplausos aliviados na cabine de passageiros. Pensamento que atravessa a equipe é de que a tensão, afinal, não era exclusiva dos pesquisadores. $O$ avião retorna pela pista de pouso até a entrada do terminal. Árvores de lado a lado e um pequeno prédio ostenta a identificação do aeroporto. Primeira etapa concluída. Mas, e o avião da segunda etapa, teria conseguido pousar? Nenhuma aeronave de porte equivalente está disponível. Imediatamente ao desembarque, inicia o embarque dos passageiros com destino a Manaus, que é feito com a mesma aeronave. Despachados os passageiros para Manaus, 


\section{OS (DES)ENCONTROS DA PESQUISA NO TEMPO-ESPAÇO AMAZÔNICO}

recebemos a notícia de que não havia outra aeronave. As condições climáticas impediram a aeronave que seguiria o voo de sair do aeroporto de origem. Resultado: escala não programada em Tefé, também para a pesquisa e um novo plano de aprendizagem abre o corpo dos pesquisadores, informados que não havia solução prevista naquele momento. Era preciso aguardar um tempo que não é cronológico, o tempo da oportunidade, que não está no âmbito da previsibilidade de quem aguarda. Nunca foi tão fácil compreender a dupla dimensão do tempo para os gregos: Chronos e Kairós ${ }^{i}$ nos oferecendo aprendizagem significativa. Agitação foi a sensação predominante: temos planos de trabalho, há um cronograma a cumprir! De nada adianta a agitação, o melhor é conectar-se com a cidade e as circunstâncias que ela oferece. O dia seguinte oferece a oportunidade esperada: um novo voo é realizado pela companhia aérea e eis que, finalmente, e com 24 horas de atraso, se chega a São Gabriel da Cachoeira. Município menor, mais distante, com um aeroporto

\footnotetext{
' O tempo, para os gregos, era designado pelas duas expressões. Chronos é o tempo sequencial, medido, com dimensão quantitativa, que tem princípio e fim. Kairós é o tempo qualitativo, refere-se a um momento indeterminado em que acontece alguma coisa especial; é o tempo da oportunidade. Também há a designação de Aíôn, que é o tempo sagrado e eterno, sem uma medida precisa.
}

menor e, igualmente, cercado de rios e floresta por todos os lados.

A chegada em São Gabriel, os procedimentos de hospedagem e os primeiros contatos com os interlocutores locais dão mostras de que a pesquisa será intensa, com o corpo sendo sensibilizado por estímulos inusitados. Nada se parece exatamente com qualquer experiência prévia. A pesquisa entra no corpo e o faz vibrar com uma grande diversidade de sensações e vivências. As atividades previstas precisam ser avaliadas e reprogramadas muito frequentemente diante das circunstâncias que fogem do controle. O que se pesquisa aqui é o que ainda não se sabe. Essa ideia mobiliza energias e aguça a vontade de iniciar.

O caminho da pesquisa: aprendendo tempos diversos e outros percursos

Na Amazônia o tempo não segue a mesma lógica do relógio; os retalhos de tempo são medidos por horas e dias de viagem, por curvas e praias do rio, por furosii, igarapés e paranásiii, pelas cheias e secas, pelo tipo de

\footnotetext{
ii Segundo Nogueira, ${ }^{3}$ em entrevista com os comandantes de barcos: "Os furos são canais de rios menores, só aparecem na cheia, atravessam as ilhas, entram nos continentes, ligam um paraná a outro".

iii Paraná constitui-se de um braço do rio com saída pela montante ou jusante no mesmo rio, constituído geralmente por uma ilha encostada a uma das margens continentais da bacia. Também há paranás rasgados entre as ilhas. $^{3}$
} 


\section{OS (DES)ENCONTROS DA PESQUISA NO TEMPO-ESPAÇO AMAZÔNICO}

acesso (avião, barco ou carro), pela potência do motor (rabetaiv $, 15,40,80,150^{v}$ ) e por tantas outras noções que dobram o tempo cronológico. A medida do tempo está na relação com o espaço, com o percorrer as distâncias entre dois pontos. Parece ser algo abstrato, mas é algo concreto; acontece cotidianamente e organiza a vida das pessoas que vivem nesses territórios. O tempo da oportunidade, de partir ou de chegar, de atravessar um percurso, de encontrar pessoas e coisas, de identificar uma árvore marcante ou um animal selvagem; essa parece ser a noção predominante de tempo. Não há sustentação no tempo cronológico do relógio. A descoberta faz com que um dos pesquisadores retire do pulso o relógio e ele passa a repousar na mochila da viagem, uma vez que esse instrumento cria uma expectativa que não se realiza plenamente no território. A nova dimensão para o tempo começa a fazer sentido no corpo e inclui a capacidade de esperar e observar.

Viajar de avião é outra experiência que não foge da dimensão singular do tempo e das

\footnotetext{
iv A rabeta é um motor de 4 ou 5 hp que tem como característica um eixo de ferro longo. É a embarcação mais comum nas comunidades ribeirinhas por ter um custo baixo.

$\checkmark$ As designações da potência do motor referem-se aos cavalos de potência (horse-power - HP) referem-se à força que o motor pode produzir para realizar o trabalho, no caso dos barcos, para o deslocamento. Ou seja, a
}

condições locais. Chegamos em Tefé para a primeira parte da viagem e logo ficamos sabendo que não seria possível seguir viagem porque o avião que faria o trajeto Tefé-São Gabriel da Cachoeira não saiu de Manaus por dificuldades técnicas. Assim, esperamos o transporte para o hotel, enquanto trocávamos impressões sobre o lugar. No aeroporto outra pessoa se incorporou ao grupo, ampliando a sua diversidade: um italiano com sotaque baiano, um gaúcho cosmopolita, um gaúcho manauara, dois paraenses-amazonenses, uma gaúcha com sotaque original e, agora, um "genuinamente" amazonense (médico gestor da atenção básica do estado). Ainda para ajudar na diversidade e no intangível, uma jornalista que tentava a todo custo um acesso de internet para submeter um projeto a um edital do Ministério da Cultura. Resultado: apesar de todo esforço, não conseguiu sinal suficiente de internet, nem mesmo andando com o computador aberto no meio da rua em busca de um sinal melhor. A conexão com a rede mundial de computadores é outra questão que passa pelo tempo-oportunidade: não é evidente que haverá conexão, tampouco que o

potência do motor também designa a velocidade possível e a expectativa de tempo de deslocamento que, como se vê, pode variar bastante. Pequenos barcos de uso pessoal e familiar costumam ter potências menores e menor capacidade de carga, com menor velocidade. Nesse caso tempo e espaço também nos ajudam a entender as desigualdades sociais no território. 


\section{OS (DES)ENCONTROS DA PESQUISA NO TEMPO-ESPAÇO AMAZÔNICO}

sinal seja suficiente para procedimentos triviais, como acessar e-mails com anexo, postar as primeiras sensações e imagens nas redes sociais e outras facilidades tecnológicas usuais na vida urbana. Usuais, porém não naturais, como parece fazer crer o excesso de uso que é naturalizado no cotidiano. Aqui, comunicação é predominantemente pela fala de pessoas, nos encontros, nas ruas, nos espaços públicos e privados.

Como não poderíamos seguir viagem, resolvemos fazer uma reunião-conversa na orla da cidade de Tefé, em frente ao lago do mesmo nome da cidade, em que circulavam lanchas, barcos e rabetas. Sentamos em volta da mesa de um dos bares e discutirmos as estratégias de pesquisa e a reorganização da agenda. Aproveitamos para conversar com 0 coordenador do Departamento da Atenção Básica (DABE/SUSAM), que atualizou as informações do grupo sobre o cenário dos profissionais médicos do Programa Mais Médicos no Amazonas. Informações da pesquisa começaram a chegar antes mesmo da "chegada em campo", e não eram informações disponíveis nas bases de dados institucionais; tratava-se de ajustes singulares do Programa à realidade local. Coisas da pesquisa qualitativa, que vai dando vida cotidiana aos dados oficiais. Impossível não lembrar de uma das dimensões da complexidade do campo da saúde coletiva que, no entendimento de Madel Luz, ${ }^{4}$ é justamente a tensão entre o conhecimento prévio e as práticas; essa tensão faz avançar o conhecimento. Não demorou muito a escurecer e presenciamos um belo espetáculo de andorinhas que se preparavam para dormir nos galhos das mangueiras que estavam acima das nossas cabeças. As andorinhas fizeram círculos e voltas no céu, com grande ruído e alvoroço, até que finalmente se acomodarem nas árvores. O espaço torna marcado por fenômenos que pertencem a forças outras: necessário retirar-se da praça que estava protegida pelas árvores, que agora se tornaram espaço de descanso e de descarga de excrementos dos pássaros. A natureza aqui mostra sua força o tempo todo. A noite está fresca e a caminhada de retorno ao hotel não é penosa; ao contrário, muito prazerosa. O sono chega com o "desligamento" da cidade, que permite a oportunidade de mais longo período de descanso em condições de temperatura mais favoráveis. A energia elétrica é fornecida por combustão (termoelétrica) e tem horários para seu funcionamento pleno. Parte da iluminação pública e a energia elétrica para a periferia da cidade, por economia, são desativadas durante a noite.

No dia seguinte, informados da solução para a viagem, seguimos para o aeroporto e, desta vez, chegamos ao destino. 


\section{OS (DES)ENCONTROS DA PESQUISA NO TEMPO-ESPAÇO AMAZÔNICO}

Partimos sem o Coordenador do DABE, que foi acionado por uma emergência. Ele retornou a Manaus para acompanhar uma pessoa com problema agudo de saúde, que teve o cuidado inicial no serviço de saúde do município por parte de uma médica que seguiu viagem conosco. A regulação do cuidado nesse território, dadas as características dos serviços disponíveis, é ainda mais dependente da mediação micropolítica. No dia seguinte, encontramos a mesma médica no Hospital Militar de São Gabriel da Cachoeira e descobrimos que estava fazendo o "rodízio" de cirurgiões militares no município. Diante da escassez de médicos interessados em atuar no hospital, sob gestão militar, a estratégia adotada foi mobilizar, por períodos de 15 dias, médicos de diferentes localidades do país para dar cobertura ao atendimento. No mesmo voo, encontramos outro médico que atuava como supervisor do PMM em área indígena. Já tinha trabalhado na região de SGC com saúde indígena e atualmente estava residindo no Nordeste. Mais registros no caderno de campo, com dados preciosos da realidade das aldeias, pelo informante inesperado. $\mathrm{O}$ inusitado, nesse caso, supre a limitação causada pelo encurtamento da estada em São Gabriel: entre os vários ajustes no cronograma, as $24 \mathrm{~h}$ em Tefé nos impediriam de realizar o campo na aldeia que planejamos. Nesse momento da viagem, diferentes situações corriqueiras no território amazônico, mas escassas em outros contextos, tomam o olhar e o corpo dos pesquisadores. O Programa Mais Médicos, a realidade da circulação de profissionais, as interfaces entre as políticas públicas e órgãos de diferentes setores, as estratégias para as fronteiras; a pesquisa começa a tomar o corpo dos pesquisadores, com depoimentos inesperados já durante a viajem. Decididamente, não se faz pesquisa sem o corpo! Pesquisa não implicada é como descobrir o já sabido; pesquisa implicada é aprendizagem, estranhamento com o corpoidentidade, transformação do conhecimento... O conhecimento, nesse caso, surge do estranhamento do percebido com o próprio corpo, com as ideias prévias e com os conhecimentos anteriores. Aprendizagem é relação de alteridade com o externo, é falseamento recíproco entre 0 já sabido/introjetado e o percebido. A pesquisa não apenas acumula registros e informações, mas também muda o modo de olhar e entender os registros.

O avião aterrissou sem problemas no aeroporto de São Gabriel (Aeroporto de Uaupés), localizado no interior da mata e completamente cercado de frondosas árvores. Tem uso comercial, mas é administrado pela Força Aérea Brasileira. Tomamos dois taxis para 


\section{OS (DES)ENCONTROS DA PESQUISA NO TEMPO-ESPAÇO AMAZÔNICO}

a cidade, que dista seis quilômetros do aeroporto. Uma constatação que nos acompanhou nos dias seguintes: os serviços, por aqui, têm uma informalidade grande e coisas práticas, como uma nota fiscal ou um recibo para comprovar a realização de um serviço não tem emissão regular. Outro inusitado: antes de chegar à cidade, tivemos que esperar pelos carros que atravessavam uma ponte improvisada pelo exército, porque a original fora levada pela chuva torrencial dos dias anteriores. O tempo, aqui, como já registrado, é marcado por oportunidades e por intervalos que não são regulares. Logo identificamos nos primeiros sinais da cidade, a forte presença do exército, justificado pela questão da fronteira e a necessidade de assegurar a soberania nacional. O local é tão estratégico para a ordem militar que tem a presença de um general. Além dos Batalhões na cidade, o exército ainda tem outros sete Pelotões de fronteira, que estão localizadas mais ao interior e junto às comunidades indígenas. O exército aqui tem um plano de transversalidade na vida da cidade, em quase todas as áreas. Inclusive na saúde, na medida em que militares administram o hospital estadual e, até o início do Programa Mais Médicos, quase toda a atenção básica do município e algo da atenção ambulatorial especializada estavam a cargo de oficiais do exército, em atividade complementar à carga horária de trabalho militar.

O caso da pesquisa propriamente dita: o Programa Mais Médicos no território do município

Assim que concluídos os procedimentos de alojamento, fomos na Secretaria Municipal de Saúde para uma conversa com o Secretário. A conversa foi bastante descontraída e produtiva. O secretário é funcionário do DSEI, mas está cedido para a gestão, sendo a segunda vez que atua como secretário. A conversa ultrapassou o roteiro previamente planejado e se estendeu para além do horário do almoço. Muitas informações sobre os componentes do sistema municipal de saúde, particularmente as dissociações em relação à saúde da população urbana e à saúde indígena, nos situou em relação aos desafios da gestão municipal e nos preparou para o que iríamos ver nos locais de serviço. A vontade de compartilhar a experiência e de contar de si e do seu trabalho tornou o roteiro prévio em tecnologia obsoleta: as respostas, com frequência, foram surgindo antes mesmo das perguntas e abrangeram aspectos que não imaginávamos existir no momento da estruturação do roteiro. Um trabalho penoso, exaustivo, muitas vezes solitário, mas mobilizado pela vontade de 


\section{OS (DES)ENCONTROS DA PESQUISA NO TEMPO-ESPAÇO AMAZÔNICO}

estruturar o SUS Municipal com as melhores condições possíveis de atendimento aos homens e mulheres daquela localidade. Trabalho militante, não por exatamente cumprir a lei, mas por acreditar que o que está previsto na lei é uma oferta boa para melhorar a saúde da população. Trabalho também engajado na mudança do contexto sanitário local. A fala contagia e quebra uma primeira sensação, de que se trata de um sistema de saúde caracterizado pela falta e pela distância em relação àquele que está no corpo e na retina dos pesquisadores: sistema de saúde urbano em grandes centros. Grita a sensação de que é preciso ajustar o corpo para compreender o que está por vir. Não é uma pesquisa que repita um movimento tautológico de buscar o já sabido e concluir que não há nada quando o que se vê não é familiar; necessário desenvolver uma sensibilidade para interagir com forte alteridade no que há para pesquisar. Há aqui um Brasil singular e, portanto, um sistema de saúde que precisa estar singularizado. É preciso ver ausências, mas também presenças singulares. Aos pesquisadores, desafia desenvolver a capacidade de ver o que não está na retina e no pensamento.

No período da tarde, visitamos a UBS da Praia, que tem esse nome porque está localizada na rua que separa a cidade do rio.
Trata-se do escuro Rio Negro, que desce pelas corredeiras e contrasta com as areias brancas praias. Nada de cachoeiras! Soube-se que o ruído das corredeiras, mimetizando quedas de água, deu o nome ao município. Um cenário para permanecer na memória... Fomos apresentados aos trabalhadores da UBS e esperamos para a entrevista com a médica cubana, uma de sete profissionais do Programa Mais Médicos no município. Esperamos pelo último atendimento para a conversa, mas o que nos admirou foi que a consulta durou em torno de 40 minutos. A espera não nos incomodou porque tivemos oportunidade de diversas conversas na Unidade e logo relacionamos com os tempos de consulta aos quais estamos habituados. Depois perguntamos à médica, qual era o tempo médio das consultas e nos respondeu que não conseguia seguir o que foi recomendado na formação inicial no Brasil, que era entre 10 a 12 minutos. Disse que ficou preocupada porque jamais conseguiria fazer num tempo tão curto. E está mais tranquila porque não precisa fazer; atende às pessoas com um tempo que se sintetiza no encontro e não está aprisionado em qualquer protocolo. Tem conseguido administrar bem a agenda, segundo nos informou e foi confirmado pelos colegas.

A entrevista foi emocionante. Depoimentos, relatos, questões mobilizadoras 


\section{OS (DES)ENCONTROS DA PESQUISA NO TEMPO-ESPAÇO AMAZÔNICO}

do pensamento, histórias da vida e o impacto da entrada no Programa. Ao saber do seu destino no Brasil, ainda em Cuba, consultou a rede mundial de computadores e encontrou várias fotos da praia. Não conseguia imaginar como haveria mar no meio da floresta, mas as imagens mostravam areias brancas e água espumosa. Conta que ao chegar, constatou que aquela água espumosa era negra. Por certo inadequada para o consumo e para o banho! Com a convivência com a população e residindo há poucos metros da praça que se continua no rio, desmistificou o imaginário construído sobre a água escura e frequenta regularmente as águas do Rio Negro em momentos de laser. Também já constatou que a vida em um território localizado no meio da floresta não é cercada de feras selvagens e perigos. É impressionante como o relato conta de descobertas, mas também de disponibilidade de descobrir, de aprendizagens, mas também de vontade de aprender. Um efeito de intercâmbio que parece não estar programado no escopo oficial do Programa, mas que, por certo, produz fluxos de trocas culturais, sanitárias e pessoais em grande quantidade. $E$ constrói laços para uma clínica singular àquela população.

A pesquisa segue e as informações continuam transbordando dos roteiros $\mathrm{e}$ atravessando o corpo e as formas prévias. $\mathrm{Na}$ sala de espera, uma senhora aguarda para conhecer a equipe de pesquisa, e soubemos que havia chegado de madrugada à UBS. Rapidamente os pesquisadores recordam que haviam captado o registro de implantação do acolhimento na unidade, o que não é compatível com o relato. Porque chegou tão cedo é o questionamento que sai automaticamente de um dos pesquisadores. Antigamente, disse a senhora, só conseguia ficha para atendimento chegando de madrugada e, como precisa fazer um deslocamento mediado por barcos e caminhadas, precisava se deslocar durante parte da noite. E agora? Agora não precisa mais, que a doutora e a equipe atendem imediatamente quando abre a unidade. $\mathrm{E}$ porque não chega mais tarde? Pois é, passou a vida toda chegando cedo ou tendo que retornar sem atendimento; não se importa de seguir nessa rotina. Senão, se um dia voltarem os tempos difíceis, não conseguirá mais se adaptar à dificuldade. Depoimento que emociona por falar de um vínculo e uma defesa do serviço de saúde que não estava entre as hipóteses iniciais. Resiliência e reconhecimento da relevância da atenção básica, que emociona. Aposta radical na atenção básica do Sistema Único de Saúde. Mas também uma dimensão do tempo-oportunidade: a gratidão por receber um bom atendimento. 


\section{OS (DES)ENCONTROS DA PESQUISA NO TEMPO-ESPAÇO AMAZÔNICO}

Depois da entrevista fomos caminhar na praia de águas negras. Algumas canoas estavam ancoradas na praia e, ao lado, estavam mãe e filha tomando seu banho diário no rio. Barcos e pescadores saindo das margens para inspecionar as redes. Fomos até o bar de um cubano, que na verdade era brasileiro, que tinha vivido na colômbia e servia comida peruana, ou seja, estávamos no local certo quando se trata de fronteira. Relatou a diversidade de fluxos na tríplice fronteira, seja para o trabalho, para o comércio, para a educação ou para a saúde, a fronteira é ponto de passagem e não de separação entre territórios, não apenas para a população indígena. Na zona de fronteira, a nacionalidade é informação com pouca capacidade de explicar diferenças culturais, idiomáticas; a fronteira é área de hibridismos. Encontros sucessivos, com roteiros que se repetem: informações sobre quem é e o que faz e logo se produz intimidade para falar de si, do contexto, das preocupações e opiniões sobre o Programa Mais Médicos. "Excelente iniciativa!", "Melhorou muito o atendimento!", "Os cubanos são muito bons" .... Opiniões que descrevem e constituem o Programa.

No dia seguinte, fomos à UBS do Centro, onde estavam dois médicos cubanos e realizamos a entrevista com ambos, ao mesmo tempo. Foi uma conversa-entrevista muito interessante, com uma diversidade de informações que surpreendeu pela clareza e pela profundidade da análise que fazem do contexto. Questionados sobre as principais marcas na chegada ao Brasil, ambos informam que o óbito de crianças por causas evitáveis, como a desnutrição, foi uma realidade partilhada por ambos. A pergunta inicialmente foi planejada para dar vazão ao que pareceu ser um primeiro evento relevante da chegada, que foi a recepção violenta a que foram submetidos por profissionais brasileiros e entidades médicas em alguns aeroportos. Não, essa informação sequer foi citada. Ver crianças desnutridas, diante de uma tão farta riqueza natural, parecia um paradoxo inaceitável para os profissionais da saúde. O que faz diante de uma cena como essa, questiona um dos pesquisadores. A resposta: não pergunto o que compõem a dieta, que é evidente não está adequada nem à criança e nem à mãe, responde o médico; pergunto o que há em casa para completar a dieta, segue o médico, e penso como posso aumentar o aporte calórico e nutricional da refeição, finaliza. Não sem, imediatamente, falar dos seus filhos, pequenos, que estão em Cuba, com olhos molhados, como dos pesquisadores. Foi inevitável a comparação com o seu país e o seu sistema de formação e de serviço de saúde. Também de ver como aprendemos a hierarquizar e naturalizar a vida 


\section{OS (DES)ENCONTROS DA PESQUISA NO TEMPO-ESPAÇO AMAZÔNICO}

que, dependendo de qual segmento da sociedade é atingido, sensibiliza mais os indicadores de morbi-mortalidade do que o corpo de quem cuida ou gere o sistema de saúde. Mas foi também uma amostra de uma clínica que tem capacidade de nomadizar-se e de uma aprendizagem que se faz mestiça com o contexto. ${ }^{5}$ Como não lembrar de pesquisas prévias e da militância por uma clínica da integralidade. O debate sobre a dimensão micropolítica do cuidado e as naturezas tecnológicas que são disponibilizadas no trabalho de cuidar, com Merhy ${ }^{6}$ quase que textualmente: a alma dos serviços de saúde é o cuidado e, para tal, uma combinação singular de tecnologias geridas com base na tecnologia relacional. O tímpano e a retina dos pesquisadores precisam estar encharcados de sensibilidade para conectar-se com o que está se passando no entorno.

No período da tarde, uma parte do grupo participou da reunião do Conselho Municipal de Saúde, cuja a pauta era a apresentação das metas do município em relação ao planejamento regional, conduzido pela Secretaria de Estado da Saúde. O Conselho é presidido por um líder indígena, que trabalhou como Agente Comunitário de Saúde por muito tempo. Ele conduziu a reunião como se dirige uma Assembleia ou Conferência, dando tempo para cada intervenção e fazendo sínteses de encaminhamento. Fizemos uma pequena exposição da pesquisa e a proposta de uma metodologia mais compartilhada sobre o PMM. Ao final, houve uma discussão sobre a presença das instituições de ensino no Conselho, pois pouco se faziam presentes e não tinham uma participação direta na política de saúde. No entanto, alguns se posicionaram no sentido de manter as instituições porque essas têm lugar importante na formação dos profissionais que atuam na saúde, inclusive respondem com o componente da formação dos trabalhadores do SUS. Esse ponto foi provocado por estudantes do curso de bacharelado em Saúde Coletiva da Universidade Estadual do Amazonas - UEA, que se apresentaram para ajudar nas análises do Conselho e teve boa acolhida na deliberação do Conselho.

A outra parte da equipe foi visitar duas UBS que tinham nas suas equipes médicos do PMM, também cubanos. Mais material riquíssimo, com relatos que apontam a saturação da amostra. Mas a vontade de seguir foi mais forte e os depoimentos captados, mesmo que com repetições relevantes. Repete o conteúdo da fala, mas não repete a ênfase, a abrangência e a intensidade do que é relatado. Aqui chamou a atenção a dificuldade de conexão à internet e, portanto, a quase impossibilidade de cumprir com as atividades 


\section{OS (DES)ENCONTROS DA PESQUISA NO TEMPO-ESPAÇO AMAZÔNICO}

da formação em EAD que os médicos estão vinculados e que são coordenadas por universidades em diversas localidades no Brasil. Aos pesquisadores, um problema se antecipa, que é o risco de interrupção do vínculo dos médicos ao Programa diante do não aproveitamento das atividades de formação. Também a constatação de que o Brasil urbano, branco e universitário desconhece os brasis que compõe, inclusive para a proposição de políticas públicas. Depois se confirmou que vários médicos do PMM no Estado foram desvinculados do Programa por não cumprirem com a programação do curso, ou seja, foram desligados por falta de comunicação numa região em que a conexão é um problema para todos os tipos de serviços e para a vida social em si.

No terceiro e último dia em São Gabriel, uma agenda intensa de visita e entrevistas. No primeiro momento, conversamos com a coordenadora da Atenção Básica, que estava no município por ser esposa de militar e tinha a formação em enfermagem. Portanto, com data para sair do município, seguindo a regra de permanência de dois anos. Assim é com parte dos profissionais do sistema municipal de saúde: a fixação é tênue e a movimentação de parte importante da equipe se dá nos ciclos da atuação nas Forças Armadas. Como não recuperar o debate sobre a importância de descentralizar a formação para o interior do país, gerando mais estímulo à fixação dos profissionais? Em seguida, visitamos o hospital militar e fomos conduzidos pelo coronel e sua equipe, com um assessor de comunicação que não deixou de registrar em muitas fotografias o roteiro da visita. A estrutura do hospital é remanescente das unidades pré-moldadas que foram importadas da Inglaterra no final da década de 1960. A unidade, apesar de antiga, estava em bom estado de conservação, em relação às outras que ainda restam no Estado, segundo informação de um dos pesquisadores que tinha estudos na área da história da saúde. O hospital tem um mamógrafo, um tomógrafo, um laboratório de exames que, por um tempo, fazia a cobertura de toda rede municipal, inclusive da saúde indígena. Com orgulho, a equipe mostra os recursos tecnológicos disponíveis e a diversidade de profissionais em diferentes áreas, inclusive na manutenção de um laboratório de saúde pública. O equipamento público de saúde, aqui, parece pintado de verde, o que dá uma dupla informação: a importância do exército na manutenção dos equipamentos de saúde e a constatação de um imaginário de que a oferta de ações de saúde é benesse.

Por fim, visitamos uma Casa de Saúde Indígena (CASAI), que é um serviço de 


\section{OS (DES)ENCONTROS DA PESQUISA NO TEMPO-ESPAÇO AMAZÔNICO}

referência para a população indígena que vive em aldeias e que necessita de procedimentos em serviços localizados na área urbana ou outras cidades. O local é uma casa de espera, de concentração e distribuição de demandas e de encontro de pessoas que procuram atendimento nas políticas públicas. Sua forma de organização se assemelha a uma pequena cidade, com pavimentos especializados (consultórios, farmácia, cozinha) e pavimentos de habitação divididos por etnia. O local está lotado, com algo em torno de 100 índios. Além das necessidades de saúde e das dificuldades de fluxo, os profissionais e índios falam de travas por preconceito, por desconhecimento da cultura, por ofertas que não dialogam com suas concepções de saúde, de desassistência e de um cenário mais promissor com a chegada dos profissionais do Programa Mais Médicos. Os relatos da realidade vivida naquele local e das histórias que os usuários contam chegam ao ouvido de parte da equipe de pesquisa inicialmente como algo próximo à ficção e, aos poucos, vão produzindo alteridade e compondo pensamentos. Para que o sistema de saúde brasileiro seja único, ele tem que ser diverso ...

À tarde tomamos carona com o avião do Estado, de 9 lugares, para retornar à Manaus, uma vez que o avião estava disponível e que nossa reunião com os representantes da Secretaria fora antecipada para horário incompatível com o voo regular (que posteriormente foi suspenso por coincidir com um feriado). O piloto nos alertou que teríamos 3 horas e meia de voo e que a aeronave não possuía sanitário e o serviço de bordo se resumia a uma caixa refrigerada com água, salgados e chocolate. A área de embarque estava vazia, pois só tinha o nosso voo para sair naquele dia. Para fazer o transporte de pacientes, é necessário arrendar os aviões regionais, o que se constitui num custo desproporcional aos recursos do município para a saúde, ou aguardar na fila do transporte sanitário do Estado, que na época era constituído por dois aviões e um hidroavião com uma equipe médica que fazem a remoção de pacientes graves nos 61 municípios do interior. O deslocamento por barco, muito demorado, normalmente torna inviável o atendimento ágil de demandas por saúde. Seguem histórias contadas pelo piloto, falando das características do território amazônico e sobre a permanente descoberta que significa transitar por aí. O avião voou sobre o rio Negro e a floresta, que alguns momentos percebemos que era branca devido às nuvens que estavam entre nós e a floresta. Assim, brincamos que a floresta dali de cima era branca. O piloto, experiente em voos naquele território, torna as formas homogêneas em histórias de aventura: pouso na água, perseguição a barcos de 


\section{OS (DES)ENCONTROS DA PESQUISA NO TEMPO-ESPAÇO AMAZÔNICO}

contrabando, salvamentos espetaculares. O tempo, nesse caso, passa mais rápido do que o relógio. O medo de voar em aviões daquele tamanho, com o manuseio da ansiedade dos passageiros feito pelo piloto, experiente, tornou-se registro de memória, apenas. Parte da equipe, soube-se depois da chegada, identificou uma capacidade ímpar do piloto em operar com tecnologias relacionais. Vontade de saber se Merhy compunha parte de suas leituras....

\section{Contexto da saúde no município}

São Gabriel da Cachoeira faz parte da região do Alto Rio Negro e a maior parte do município compreende a área indígena do Rio Negro, que se estende para os municípios de Barcelos e Santa Izabel. Parte da área indígena Yanomami também faz parte do território do município. A região do Rio Negro é compartilhada por 22 etnias, que pertencem a quatro famílias linguísticas (Tukano Oriental, Maku, Aruak, Yanomami), tendo ainda a Língua Geral (Nhengatu) como um idioma falado por alguns grupos. A diversidade linguística se reflete nas diferenças cosmogônicas e cosmológicas. ${ }^{7}$ Os grupos da família linguística Tukano Oriental estão divididos em quinze grupos patrilineares exogâmicos: Arapaço, Bará, Barasana, Desana, Cubeo, Karapaná,
Makuna, Miriti-tapuia, Pira-tapuia, Siriano, Taiwano, Tatuyo, Tukano, Tuyuka, Yuriti, etc. ${ }^{8}$

A cidade de SGC se constitui numa grande babel, pois é um território de encontro e a sede do poder e da gestão das políticas públicas e das políticas indígenas de parte importante da população que vive no Amazonas. Vimos na Casa de Saúde Indígena (CASAI) a política em ação, pois ali estavam os usuários e suas famílias nos alojamentos aguardando o atendimento na rede municipal ou o deslocamento para Manaus. Vimos a preocupação do gestor com o ambiente para que o indígena se sentisse mais próximo possível do seu mundo. Observamos também a preocupação de separar as etnias para evitar problemas e também para respeitar as diferenças linguísticas. A CASAI, como um microcosmo, representa muito bem o universo da região do Alto Rio Negro. A população indígena é diversa em termos de cultura, língua e modos de organizar a vida e a saúde e leva suas características nos territórios por onde passa.

A convivência dessas características torna o território altamente complexo e essa complexidade precisa estar presente nas respostas das políticas públicas. Como exemplo: o sistema de casamento no tronco Tukano (maioria no Rio Negro) é do tipo 


\section{OS (DES)ENCONTROS DA PESQUISA NO TEMPO-ESPAÇO AMAZÔNICO}

patrilinear e exogâmico linguístico. $\mathrm{O}$ casamento sempre deve ser realizado entre etnias diferentes, e a mulher deve deixar a casa dos pais para viver com o marido. Isso significa dizer que numa mesma localidade as mulheres sejam de diversas etnias e os homens de uma mesma etnia. Esse sistema mantém sempre em aberto a possibilidade de alianças e acordos políticos para o equilíbrio das forças. Assim, as funções de liderança e coordenação tanto tradicionais (Tuxaua, Pajé) como novos (líder comunitário, presidente da associação, Agente Comunitário Indígena, chefe do posto) representam locais de poder que estão diretamente relacionados aos contextos sóciolinguísticos.

A região é marcada historicamente pela presença de algumas instituições, sendo a Igreja Católica, através das missões salesianas, a que teve um maior impacto na vida social das comunidades. Os missionários salesianos se instalaram de modo permanente na região do Alto Rio Negro a partir de 1915, e organizaram as aldeias pelo princípio de comunidades, com casas ordenadas em fileiras de ruas. Os missionários construíram internatos em diferentes áreas com o objetivo de educar as crianças a partir de padrões e princípios cristãos e ocidentais. A Diocese tinha uma rede de ambulatórios e postos nas comunidades indígenas, inclusive com uma unidade de saúde e escola. Com a mudança na política de saúde e com a criação do sistema de saúde indígena, a igreja foi participando menos na gestão da saúde. Ainda participa da organização do sistema de saúde indígena, tendo papel de articuladora junto às organizações indígenas do Rio Negro. O exército é outra instituição que tem influência sobre a região. Na questão da saúde, o hospital é de gestão militar através de convênio com a Secretaria de Estado de Saúde, tendo um quadro próprio de profissionais. Nos pelotões de fronteira há a presença dos profissionais de saúde, que, em parte, realizam a assistência aos indígenas, pois a responsabilidade é do Distrito Sanitário Especial Indígena, que nem sempre acompanha a mobilidade e a dispersão das populações.

A saúde no município está dividida em três partes: gestão municipal que é responsável pelas UBS da sede; saúde indígena de responsabilidade federal e realiza a gestão do DSEI e da CASAl; hospital militar que é uma instituição federal em convênio com o Estado. Portanto, temos a gestão municipal, estadual e federal no mesmo município. Isso exige um diálogo entre esses entes, tanto no que se refere às informações como na negociação da própria atenção à população.

De toda forma, há um consenso de que o Programa Mais Médicos ofereceu um marco 


\section{OS (DES)ENCONTROS DA PESQUISA NO TEMPO-ESPAÇO AMAZÔNICO}

de desenvolvimento do sistema de saúde: a grande expansão de cobertura assistencial, com o provimento de profissionais antes muito escassos; uma maior integração com aspectos singulares dos modos de vida das populações, em parte devida a uma clínica com mais escuta aos aspectos envolvidos com a produção de saúde e que são particulares nos territórios; o fortalecimento da função de gestão do sistema de saúde, com maior presença e integração da esfera estadual e federal. Diversos problemas continuam existindo e, provavelmente, o principal deles é o risco de descontinuidade do Programa, que gera uma dupla consequência: a interrupção de uma iniciativa que se mostrou capaz de enfrentar a problemática da desassistência ou do enorme esforço local para viabilizar atendimento e a redução na oferta assistencial, que já está incorporada no cotidiano como função do sistema de saúde e, provavelmente, como direito das pessoas. Definitivamente, analisar os efeitos do Programa Mais Médicos nesse local exige mais do que o conhecimento da estatística, da epidemiologia e das políticas de saúde.

Conclusões. Ou: o embrenhamento como oportunidade ao pensamento

Como registrado no início, nos embrenhamos para essa etapa da pesquisa. Mais do que o resultado em si, que vai compondo nossa produção científica para debate com a comunidade acadêmica, interessou aqui uma reflexão sobre o fazer $d a$ pesquisa. A produção em termos de tecnologias, conhecimentos e informações técnico-científicas, para disseminação e consolidação do campo de pesquisas, para informação aos tomadores de decisão e aos militantes por políticas públicas, vai se tornando disponível na medida em que os resultados são consolidados e aceitos para publicação e apresentação. Afinal, a interlocução contínua com a comunidade científica e com pessoas interessadas em determinado assunto é o que desenvolve um campo de conhecimentos e o que torna válida e útil a produção acadêmica. ${ }^{9}$ Já não se sustenta a validade da pesquisa apenas no primado do método ("obsessão metodológica") e na crença de objetividade e racionalidade da ciência, lembra Alvez-Mazzotti ${ }^{9}$ e, por isso, a circulação do conhecimento produzido é muito importante.

Entretanto, aqui a vontade era de refletir sobre 0 processo de pesquisa propriamente dito. Sobre o embrenhamento na pesquisa em si. Sobre a capacidade do "campo empírico" em produzir as necessárias dobras do pensamento do pesquisador e da porosidade dos recursos metodológicos utilizados na 


\section{OS (DES)ENCONTROS DA PESQUISA NO TEMPO-ESPAÇO AMAZÔNICO}

pesquisa de se abrir às singularidades do empírico.

A questão que surge é a ideia de que não cabe aqui uma teoria totalizadora e, sim, a nutrição de um olhar questionador, pois a segurança dos conceitos naturalizados, duros e lacrados em caixotes, tem efeito de sedação à capacidade de criação, à inovação, ao viver saúde e ao exercício permanente de viver em intensidade. ${ }^{10}$ Ao mesmo tempo que se faz uma boa "revisão da literatura" ou um excelente retrato do "estado da arte" da temática em estudo, é preciso constituir dúvidas sobre a capacidade da teoria de dialogar com a prática. É preciso questionar se, em última análise, o conhecimento produzido tem capacidade de compor uma "caixa de ferramentas". Esse termo é tomado por empréstimo de um diálogo entre Deleuze e Foucault ${ }^{11}$ em que debatem as relações de transversalidade entre teoria e prática: "desde que uma teoria penetra em determinado ponto, ela se choca com a impossibilidade de ter a menor consequência prática sem que se produza uma explosão."11:71 A questão que se deve fazer à teoria é se ela serve, se funciona, se explode a ponto de se deixar atravessar pelos desafios que o cotidiano coloca ao trabalho intelectual. Para Deleuze, "Se não há pessoas para utilizá-la, a começar pelo próprio teórico que deixa então de ser teórico, é que ela não vale nada ou que o momento ainda não chegou." ${ }^{11} \mathrm{O}$ momento da exposição ao campo empírico é uma ótima oportunidade de fazer funcionar a teoria, de questionar o quanto ela serve para aquele contexto. Nossos registros nos cadernos de campo foram rico material empírico para captar os estranhamentos do cotidiano observado com conhecimentos e "objetividades" prévias.

Nessa perspectiva, o embrenhamento no território marcado pela floresta tropical foi revelador de novidades ao pensamento e de novas perspectivas para analisar as práticas de cuidado, bem como apontam para o próprio modo de fazer pesquisa. A diversidade local, somada à sensibilidade na escuta dos profissionais que se agregaram ao Programa Mais Médicos parece revelar uma dimensão impensada na política oficial: o desenvolvimento do trabalho no cotidiano da atenção básica. Diferentes teorias e práticas chocam-se e geram o desenvolvimento da capacidade de gerir e cuidar. A pesquisa se reinventa no ato de pesquisar, entre o plano de trabalho, os desafios e os imprevistos. Só há pesquisa, se o pesquisador se reinventa e aos seus métodos de coletar e interpretar os dados e, portanto, a pesquisa é em si educação permanente. 


\section{Referências}

1.Ferreira ABH. Pequeno Dicionário Brasileiro de Língua Portuguesa. 11 ed. rev. e ampl. Rio de Janeiro: Civilização Brasileira, 1964.

2.Nicoli MA, Martino A, Marta BL, Baptista GC, Guimarães CF, Sintoni F, Ferla AA. Não é só um problema de "satisfação dos usuários": considerações sobre a participação dos usuários na avaliação da atenção básica. Saúde em Redes [Internet]. 2016 [15 jan 2017]; 2(1):23-42. Disponível em: http://revista.redeunida.org.br/ojs/index.php/rede-unida/article/view/658/pdf_21

${ }^{3}$.Nogueira ARB. Percepção e representação gráfica: a "geograficidade" nos mapas mentais dos comandantes de embarcações no Amazonas. Manaus: Edua, 2014.

${ }^{4}$.Luz MT. Complexidade do campo da saúde coletiva: multidisciplinaridade, interdisciplinaridade e transdisciplinaridade de saberes e práticas - análise sócio-histórica de uma trajetória paradigmática. Saúde e Sociedade [Internet]. $2009 \quad[15 \quad$ jan 2017];18(2):304-311. Disponível em: http://www.scielo.br/pdf/sausoc/v18n2/13.pdf.

5. Ferla AA. Clínica em movimento: cartografias do cuidado. Caxias do Sul: EDUCS, 2007.

${ }^{6}$.Merhy EE. Educação Permanente em Movimento - uma política de reconhecimento e cooperação, ativando os encontros do cotidiano no mundo do trabalho em saúde, questões para os gestores, trabalhadores e quem mais quiser se ver nisso. Saúde em Redes [Internet]. 2015[15 jan 2017];1(1):07-14. Disponível em: http:// revista.redeunida.org.br/ojs/index.php/rede-unida/article/view/309/15.

7.Schweickardt JC, Gentil G. A "manjuba" e o encanto: relação natureza-cultura na explicação da doença. Boletim Rede Amazônia. 2014; 3(1): 47-54.

8.Buchillet D. Os Índios da região do Alto Rio Negro: história, etnografia e situação fundiária. Laudo antropológico pela Procuradoria Geral da República. Brasília: 1997.

${ }^{9}$.Alves-Mazzotti AJ. Usos e abusos dos estudos de caso. Cadernos de Pesquisa. 2006 set-dez; 36(129): 637-651.

${ }^{10}$.Collar JM, Almeida-Neto JB, Ferla AA. Educação Permanente e o cuidado em saúde: ensaio sobre o trabalho como produção inventiva. Saúde em Redes [Internet]. 2015[15 jan 2017]; 1(4):53-64. Disponível em: http://revista.redeunida.org.br/ojs/index.php/rede-unida/article/view/644/pdf_15

${ }^{11}$.Foucault M. Microfísica do Poder. 8.ed. Rio de Janeiro: Edições Graal, 1989. 